\title{
Docosahexaenoic Acid Is the Preferred Dietary n-3 Fatty Acid for the Development of the Brain and Retina ${ }^{1}$
}

\author{
GREGORY J. ANDERSON, WILLIAM E. CONNOR, AND JULIE D. CORLISS
}

Department of Medicine, Oregon Health Sciences University, Portland, Oregon 97201

\begin{abstract}
The metabolism of individual dietary $n-3$ fatty acids was studied in n-3 fatty acid-deficient newly hatched chicks. Laying hens were fed the n-6 fatty acid, ethyl linoleate, as the only source of polyunsaturated fat. Chicks were then fed the n-3-deficient hens' diet, or one of three other diets supplemented with the ethyl ester of 18:3n-3, 20:5n-3 [eicosapentaenoic acid (EPA)], or 22:6n3 [docosahexaenoic acid (DHA)] at $0.44 \%$ of calories. At the end of $0,1,2$, and 3 wk, the fatty acid composition of the brain, retina, liver, and serum was determined. Dietary EPA and DHA were equally effective at raising levels of DHA in the brain and retina. Dietary 18:3 was relatively ineffective in restoring brain and retina DHA. In the n-3deficient chicks fed EPA or DHA, levels of DHA recovered to control values in both the brain and retina by 3 wk. Very little EPA accumulated in the brain or retina of chicks fed EPA. Hepatic synthesis of DHA from EPA appeared low, suggesting that the brain and retina synthesized the DHA that accumulated rapidly in these tissues after the feeding of EPA. The $\delta$-4-desaturase enzyme was apparently very active, then, in the brain and retina. Retroconversion of dietary $22: 6$ to $22: 5$ and $20: 5$ was evident in the serum, liver, and retina but not in the brain. Thus, it was possible to study the relative metabolism and especially the interconversion of n-3 fatty acids in a environment uncomplicated by existing stores of these essential fatty acids. This study would suggest that $18: 3$ as the sole source of $n-3$ fatty acids in the diets of animals, including the human infant, may not be adequate for the biochemical development of the brain and retina and that dietary DHA is the preferred fatty acid of the n-3 series. (Pediatr Res 27: 8997, 1990)
\end{abstract}

\section{Abbreviations}

DHA, docosahexaenoic acid

EPA, eicosapentaenoic acid

The n-3 family of polyunsaturated fatty acids has become the focus of much interest because of evidence that these compounds

Received July 5, 1989; accepted August 23, 1989.

Correspondence Dr. Gregory J. Anderson, Department of Medicine, Oregon Health Sciences University, Portland, OR 97201.

Supported by NIH Grants HL37940, DK29930, DK40935, and RR00334 and a research fellowship (G.J.A.) from the American Heart Association, Oregon Affiliate.

${ }^{1}$ Presented in preliminary form at the 1989 meeting of the Federation of American Societies for Experimental Biology. are antiatherogenic $(2,3)$ and may also be essential nutrients. Deficiencies of $n-3$ fatty acids in the diet lead to disturbances in behavior, deficient vision, and abnormal electroretinograms (48). DHA (22:6n-3), a 22 carbon $n-3$ fatty acid, is especially concentrated in the brain and retina. The need of these nervous tissues for DHA, and the fact that this 22 carbon fatty acid can be synthesized from the precursors $\alpha$-linolenic acid (18:3n-3) and EPA, has given rise to the question of which fatty acid in the $n-$ 3 series would most rapidly be taken up by the brain and retina. Is DHA the preferred fatty acid or would the body synthesize DHA from EPA or linolenic acid, such that brain and retinal DHA accumulate as readily from these precursors in the diet as from dietary DHA?

The purpose of this experiment was to produce n-3-deficient newly hatched chicks and then to replete their brains and retinas by feeding one of three different n-3 fatty acids: DHA, EPA or $\alpha$-linolenic acid. Such an experiment would test the relative ability of the brain, retina, and liver to synthesize DHA from precursors and would reveal the relative retroconversion of the longer chain fatty acids into shorter chain fatty acids. Such information would provide a tissue benchmark for estimating the ideal fatty acid composition of infant formulas which currently provide only $\alpha$-linolenic acid.

\section{MATERIALS AND METHODS}

Design and diets. n-3 fatty acid-deficient eggs were produced by the feeding of an n-3 fatty acid-free diet to laying hens of the white leghorn variety for 2 mo. This diet consisted of a casein/ dextrose-based fat-free basal mix (9) supplemented with $10 \%$ fat by weight, including $5 \%$ of calories from ethyl linoleate $(18: 2 n-$ $6)$, to prevent $n-6$ essential fatty acid deficiency, with the balance of the fat from hydrogenated coconut oil. Control hens received commercial food for laying hens. Eggs were collected and incubated as previously described (9).

Four groups of newly hatched n-3 fatty acid-deficient chicks were fed an n-3 fatty acid-deficient diet or one of three repletion diets for 1, 2, or 3 wk. The deficient diet consisted of a casein/ dextrose-based fat-free basal mix for chicks supplemented with $5 \%$ fat by weight (Table 1), including 3\% of calories from ethyl linoleate and the balance of the fat from hydrogenated coconut oil. The repletion diets consisted of the same n-3 fatty acid deficient diet, but supplemented with $0.44 \%$ of calories from ethyl esters of either 18:3n-3, EPA, or DHA. For the 18:3n-3 diet, which was prepared using ethyl esters from soybean oil, the amount of added ethyl linoleate was reduced, to compensate for the $18: 2 n-6$ present in the soybean oil. A group of control chicks received a commercial chick starter containing $3 \%$ fat. All semipurified diets contained $0.02 \%$ t-butylhydroquinone and 
Table 1. Composition of diet fed to newly hatched chicks

\begin{tabular}{lr} 
& $\mathrm{g} / 100 \mathrm{~g}$ \\
\hline Dextrose monohydrate & 62.33 \\
Fat free casein & 26.32 \\
L-Arginine HCl & 1.26 \\
DL-Methionine & 0.42 \\
Cellulose & 3.16 \\
Salt mix* & 6.11 \\
Vitamin mix $\dagger$ & 0.41 \\
Fatł & 5.00 \\
\hline
\end{tabular}

* Salt mix (per $100 \mathrm{~g}$ diet): $3.6 \mathrm{~g} \mathrm{CaHPO} \cdot 2 \mathrm{H}_{2} \mathrm{O}, 0.87 \mathrm{~g}$ potassium citrate $\cdot \mathrm{H}_{2} \mathrm{O}, 0.79 \mathrm{~g} \mathrm{CaCO}_{3}, 0.54 \mathrm{~g} \mathrm{NaCl}, 0.15 \mathrm{~g} \mathrm{MgO}, 95 \mathrm{mg}$ ferric citrate, $33 \mathrm{mg} \mathrm{MnSO}_{4} \cdot \mathrm{H}_{2} \mathrm{O}, 19 \mathrm{mg} \mathrm{ZnCO}_{3}, 6.3 \mathrm{mg} \mathrm{CuSO} \mathrm{m}_{4} \cdot 5 \mathrm{H}_{2} \mathrm{O}, 3.1$ mg CrK $\left(\mathrm{SO}_{4}\right)_{2} \cdot 12 \mathrm{H}_{2} \mathrm{O}, 0.95 \mathrm{mg} \mathrm{KIO}, 0.26 \mathrm{mg} \mathrm{Na} \mathrm{MoO}_{4} \cdot 2 \mathrm{H}_{2} \mathrm{O}$ $\mathrm{Na}_{2} \mathrm{SeO}_{3} \cdot 5 \mathrm{H}_{2} \mathrm{O}$.

$\dagger$ Vitamin mix (per $100 \mathrm{~g}$ diet): $375 \mathrm{mg}$ choline bitartrate, $6.3 \mathrm{mg}$ niacin, $5.3 \mathrm{mg}$ vitamin $\mathrm{B}_{12}, 3.2 \mathrm{mg}$ calcium pantothenate, $2.1 \mathrm{mg}$ thiamin $\cdot \mathrm{HCl}, 1.7 \mathrm{mg}$ menadione sodium bisulfite complex, $1.6 \mathrm{mg}$ pyridoxine $\cdot \mathrm{HCl}, 1.6 \mathrm{mg}$ riboflavin, $0.4 \mathrm{mg}$ folic acid, $50 \mu \mathrm{g}$ biotin, 10.5 $\mathrm{mg}$ vitamin $\mathrm{E}$ acetate $(500 \mathrm{U} / \mathrm{g}), 2.1 \mathrm{mg}$ vitamin A palmitate $(500,000$ $\mathrm{U} / \mathrm{g}), 0.6 \mathrm{mg}$ vitamin $\mathrm{D}_{3}(500,000 \mathrm{U} / \mathrm{g})$.

$¥$ Ethyl linoleate, hydrogenated coconut oil, and an $n-3$ fatty acid (see text).

Table 2. Fatty acid composition (wt\%) of control, $n$-3 fatty aciddeficient, and repletion diets

\begin{tabular}{|c|c|c|c|c|c|}
\hline & $\begin{array}{c}\text { Control } \\
\text { diet }\end{array}$ & $\begin{array}{c}n-3 \\
\text { deficient }\end{array}$ & $\begin{array}{c}\text { Deficient } \\
+18: 3\end{array}$ & $\begin{array}{c}\text { Deficient } \\
+20: 5 \\
\end{array}$ & $\begin{array}{c}\text { Deficient } \\
+22: 6\end{array}$ \\
\hline $12: 0$ & 0.4 & 27.9 & 27.7 & 32.8 & 36.5 \\
\hline 14:0 & 1.3 & 20.0 & 10.8 & 14.3 & 15.6 \\
\hline $16: 0$ & 23.0 & 10.7 & 10.8 & 7.3 & 7.4 \\
\hline $18: 0$ & 7.9 & 9.4 & 7.3 & 8.6 & 7.7 \\
\hline Total sat. & 34.8 & 68.3 & 60.2 & 66.4 & 70.5 \\
\hline $18: 1 n-9$ & 33.2 & 0.5 & 9.6 & 0.1 & 0.3 \\
\hline Total mono. & 36.7 & 0.8 & 9.8 & 0.1 & 0.6 \\
\hline $\begin{array}{l}18: 2 n-6 \\
20: 4 n-6\end{array}$ & 25.9 & 30.9 & 26.5 & $\begin{array}{r}29.6 \\
0.2\end{array}$ & 24.2 \\
\hline Total n-6 & 25.9 & 30.9 & 26.5 & 29.8 & 24.3 \\
\hline $18: 3 n-3$ & 1.3 & & 3.5 & & \\
\hline $20: 5 n-3$ & & & & 3.6 & 0.03 \\
\hline $22: 5 n-3$ & & & & & 0.26 \\
\hline $22: 6 n-3$ & & & & & 3.7 \\
\hline $\begin{array}{l}\text { Total n-3 } \\
\text { Ratio }\end{array}$ & 1.3 & & 3.5 & 3.6 & 4.0 \\
\hline$n-6 / n-3$ & 19.9 & High & 7.6 & 8.3 & 6.1 \\
\hline
\end{tabular}

were handled so as to minimize oxidation of the polyunsaturated fat (9). There was no significant difference in the growth of chicks on the various experimental diets (data not shown), and growth was comparable to that reported for white leghorn chicks (10). The fatty acid composition of the control and experimental diets fed to the chicks is shown in Table 2 .

At the designated time periods, chicks were killed, lipids extracted, and the fatty acid composition of the brain, retina, liver, and serum determined as previously described (9). Fatty acid values are reported as percent of total fatty acids, by weight. Complete fatty acid composition data are available from the authors on request.

t-Butylhydroquinone was purchased from Eastman Kodak,
Rochester NY. Ethyl esters of EPA and DHA were the gift of Prof. Akira Kumagai (Toyama City, Japan), and the hydrogenated coconut oil was donated by Palmco., Inc., (Portland, OR). Ethyl linoleate was obtained from NuChekPrep (Elysian, MN). Fat-free basal mixes for chicks and laying hens were obtained from Teklad, Madison, WI. Ethyl esters of soybean oil were synthesized by refluxing $60 \mathrm{~g}$ of oil in $4 \% \mathrm{H}_{2} \mathrm{SO}_{4}$ in ethanol (vol/ vol) for $90 \mathrm{~min}$, followed by extraction with hexane and washing with $2 \% \mathrm{NaHCO}_{3}(11)$. This preparation showed only one spot, corresponding to fatty acid ester, after silica gel thin-layer chromatography with hexane: $\mathrm{CHCl}_{3}$ :ethyl ether:acetic acid $(80: 10: 10: 1.5)$. The fatty acid composition was identical to that of soybean oil and the yield was quantitative.

Statistical analyses. Comparison of the effect of the diets on tissue levels of DHA, total n-3 fatty acids, and 22:5n-6 was done using two-way analysis of variance ("Stata" statistics package from The Computing Resource Center, Los Angeles, CA). The data were first $\log$ transformed, because the raw data failed the Bartlett test for unequal variances. Differences between individual means were detected by use of the appropriate $t$ statistic (12), using the BonFerroni inequality (13) to control the overall $\alpha$-level.

\section{RESULTS}

Brain and retina. The brain and retinal DHA of $n-3$ fatty aciddeficient chicks increased rapidly after the addition of either EPA or DHA to the diet (Tables 3 and 4). Levels of DHA rose to values of control chicks or higher by 3 wk of refeeding with either of these fatty acids. These changes indicated that the chick was able to use EPA efficiently as a substrate to synthesize DHA. However, dietary 18:3n-3 was only one-third as effective as either EPA or DHA in increasing levels of DHA in these tissues. The repletion of DHA led also to a reduction of $22: 5 n-6$, a fatty acid that accumulates in $\mathrm{n}-3$ deficiency. This decrease was significantly slower in the 18:3 diet group. A graphical representation of the relative effectiveness of the three repletion diets in increasing brain and retinal DHA, and lowering brain $22: 5 n-6$, is shown in Figures 1-3.

Very little EPA accumulated in the brain or retina in any of the diet groups, with the exception of the retina of 1 -wk-old chicks fed the EPA diet. This amounted, however, to only $0.4 \%$ of total fatty acids, and decreased rapidly by wk 2 and 3 . Some EPA was formed in the retina as result of retroconversion of DHA in the DHA-fed chicks. In fact, a nontrivial fraction of the total n-3 fatty acids in the retina of 3-wk-old chicks fed the DHA diet consisted of retroconversion products of DHA (i.e. 22:5n-3, EPA, and 18:3n-3). In contrast, these retroconversion products were generally not found in the brain.

Levels of arachidonic acid, 20:4n-6, were not affected by either the deficiency of n-3 fatty acids or the rapid assimilation of DHA into the brain and retina. Previous studies had shown a pronounced lowering of tissue $20: 4 n-6$ in response to dietary DHA and EPA, albeit at high doses fed to animals already possessing normal stores of n-3 fatty acids (14-18).

Serum and liver. The similarity in the effects of dietary EPA and DHA in the brain and retina did not extend to the serum (Table 5). In fact, for the first 2 wk most of the total $n-3$ fatty acids in the serum of chicks fed EPA remained as EPA. Serum levels of DHA were much lower in the EPA group at all time periods than in those animals fed DHA directly. In the 18:3-fed group, levels of DHA in the serum were lower still. Total n-3 fatty acids in this diet group were also substantially lower than total serum n-3 fatty acids in the chicks fed either EPA or DHA. Interestingly, a substantial fraction of the dietary DHA was retroconverted, presumably in the liver, as evidenced by the 
Table 3. Brain fatty acid composition (wt\%) after refeeding of $n$-3-deficient chicks with 18:3, 20:5, or 22:6 for 1, 2, and 3 wk

\begin{tabular}{|c|c|c|c|c|c|c|c|c|c|c|c|c|c|c|c|c|c|}
\hline & \multicolumn{4}{|c|}{ Control diet } & \multicolumn{4}{|c|}{ Deficient diet* } & \multicolumn{3}{|c|}{ Deficient diet $+18: 3$} & \multicolumn{3}{|c|}{ Deficient diet + EPA } & \multicolumn{3}{|c|}{ Deficient diet + DHA } \\
\hline & \multicolumn{4}{|c|}{ Wk } & \multicolumn{4}{|c|}{$\mathrm{Wk}$} & \multicolumn{3}{|c|}{ Wk } & \multicolumn{3}{|c|}{ Wk } & \multicolumn{3}{|c|}{$\mathrm{Wk}$} \\
\hline & 0 & 1 & 2 & 3 & 0 & 1 & 2 & 3 & 1 & 2 & 3 & 1 & 2 & 3 & 1 & 2 & 3 \\
\hline $\begin{array}{l}16: 0 \\
18: 0\end{array}$ & $\begin{array}{l}32.4 \pm 2.6 \\
19.5 \pm 1.0\end{array}$ & $28.5 \pm 2.5$ & $25.4 \pm 1.2$ & $24.4 \pm 0.8$ & $32.2 \pm 4.7$ & $32.4 \pm 4.0$ & $28.4 \pm 0.6$ & & $28.6 \pm 1.4$ & $28.6 \pm 2.7$ & $29.0 \pm 4.0$ & $31.3 \pm 3.4$ & $27.7 \pm 2.2$ & $24.8 \pm 2.3$ & $30.8 \pm 2.9$ & $28.1 \pm 2.7$ & $25.4 \pm 3.2$ \\
\hline $\begin{array}{l}18: 0 \\
\text { Total sat. }\end{array}$ & $\begin{array}{l}19.5 \pm 1.0 \\
52.6 \pm 3.1\end{array}$ & $\begin{array}{l}19.7 \pm 0.7 \\
49.3 \pm 2.5\end{array}$ & $\begin{array}{l}17.8 \pm 2.7 \\
46.4 \pm 2.4\end{array}$ & $\begin{array}{l}18.8 \pm 1.1 \\
44.2 \pm 0.2\end{array}$ & $\begin{array}{l}16.9 \pm 0.5 \\
50.9 \pm 5.0\end{array}$ & $\begin{array}{l}16.7 \pm 0.6 \\
51.4 \pm 5.4\end{array}$ & $\begin{array}{l}16.4 \pm 4.6 \\
47.6 \pm 2.3\end{array}$ & $\begin{array}{l}17.2 \pm 0.4 \\
43.9 \pm 3.2\end{array}$ & $\begin{array}{l}15.9 \pm 1.0 \\
45.6 \pm 1.6\end{array}$ & $\begin{array}{l}17.7 \pm 2.4 \\
45.2 \pm 0.6\end{array}$ & $\begin{array}{l}18.8 \pm 1.3 \\
48.6 \pm 4.5\end{array}$ & $\begin{array}{l}16.4 \pm 0.3 \\
49.9 \pm 3.5\end{array}$ & $\begin{array}{l}16.8 \pm 4.0 \\
45.2 \pm 3.9\end{array}$ & $\begin{array}{l}17.3 \pm 0.9 \\
42.7 \pm 3.1\end{array}$ & $\begin{array}{l}16.8 \pm 2.8 \\
49.3 \pm 2.3\end{array}$ & $\begin{array}{l}19.4 \pm 2.2 \\
48.4 \pm 2.6\end{array}$ & $\begin{array}{l}17.3 \pm 1.1 \\
43.2 \pm 4.1\end{array}$ \\
\hline $16: 1 \mathrm{n}-7$ & $1.4 \pm 0.7$ & $1.5 \pm 0.8$ & $1.4 \pm 0.1$ & & & & & & & & & & & & & & \\
\hline $18: 1 n-9$ & $16.2 \pm 1.1$ & $20.1 \pm 0.3$ & $22.3 \pm 0.7$ & $\begin{array}{r}1.2 \pm 0.1 \\
23.8 \pm 0.4\end{array}$ & $\begin{array}{r}1.5 \pm 0.2 \\
15.6 \pm 0.2\end{array}$ & $\begin{array}{r}2.0 \pm 0.6 \\
19.2 \pm 1.1\end{array}$ & $\begin{array}{r}1.8 \pm 0.3 \\
19.5 \pm 1.0\end{array}$ & $\begin{array}{r}1.1 \pm 0.1 \\
24.4 \pm 0.9\end{array}$ & $\begin{array}{r}1.9 \pm 0.5 \\
21.0 \pm 0.6\end{array}$ & $\begin{array}{r}1.8 \pm 0.2 \\
22.3 \pm 0.6\end{array}$ & $\begin{array}{r}1.5 \pm 0.3 \\
21.5 \pm 3.0\end{array}$ & $\begin{array}{r}1.3 \pm 0.2 \\
19.0 \pm 0.2\end{array}$ & $\begin{array}{r}1.3 \pm 0.3 \\
20.2 \pm 0.8\end{array}$ & $\begin{array}{r}1.2 \pm 0.4 \\
21.2 \pm 1.2\end{array}$ & $\begin{array}{r}1.6 \pm 0.4 \\
19.7 \pm 0.9\end{array}$ & $\begin{array}{r}1.1 \pm 0.3 \\
20.1 \pm 1.1\end{array}$ & $\begin{array}{r}1.0 \pm 0.2 \\
23.4 \pm 4.2\end{array}$ \\
\hline Total mono. & $18.4 \pm 2.1$ & $22.5 \pm 0.7$ & $25.8 \pm 2.0$ & $25.8 \pm 0.2$ & $17.7 \pm 0.0$ & $21.8 \pm 1.5$ & $22.4 \pm 1.4$ & $26.4 \pm 0.9$ & $23.7 \pm 0.8$ & $25.0 \pm 0.5$ & $23.9 \pm 3.4$ & $21.0 \pm 0.1$ & $21.9 \pm 1.0$ & $23.2 \pm 1.2$ & $22.3 \pm 1.1$ & $23.7 \pm 4.3$ & $22.8 \pm 2.4$ \\
\hline $20: 3 n-9$ & $0.2 \pm 0.1$ & $1.7 \pm 0.1$ & $2.8 \pm 0.3$ & $2.5 \pm 0.3$ & $0.2 \pm 0.0$ & $1.5 \pm 0.5$ & $1.5 \pm 0.3$ & $1.8 \pm 0.8$ & $1.0 \pm 0.2$ & $1.5 \pm 0.5$ & $0.9 \pm 0.3$ & $0.9 \pm 0.3$ & $0.9 \pm 0.3$ & $0.7 \pm 0.4$ & $0.8 \pm 0.5$ & $0.7 \pm 0.2$ & $0.7 \pm 0.3$ \\
\hline $\begin{array}{l}18: 2 n-6 \\
20: 4 n-6\end{array}$ & $\begin{array}{l}1.4 \pm 0.1 \\
9.3 \pm 1.1\end{array}$ & $0.7 \pm 0.0$ & $0.7 \pm 0.1$ & $0.6 \pm 0.0$ & $1.5 \pm 0.1$ & $0.9 \pm 0.2$ & $0.9 \pm 0.1$ & $0.8 \pm 0.1$ & $1.1 \pm 0.1$ & $1.0 \pm 0.1$ & $0.8 \pm 0.2$ & $0.9 \pm 0.2$ & $0.7 \pm 0.1$ & $0.6 \pm 0.1$ & $0.8 \pm 0.1$ & $0.7 \pm 0.2$ & $0.7 \pm 0.1$ \\
\hline $\begin{array}{l}20: 4 n-6 \\
22: 4 n-6\end{array}$ & $\begin{array}{l}9.3 \pm 1.1 \\
2.3 \pm 0.5\end{array}$ & $\begin{array}{l}8.8 \pm 0.8 \\
2.4 \pm 0.3\end{array}$ & $\begin{array}{l}8.4 \pm 0.9 \\
2.2 \pm 0.2\end{array}$ & $9.6 \pm 0.4$ & $10.8 \pm 1.0$ & $9.8 \pm 0.9$ & $11.6 \pm 2.2$ & $11.2 \pm 1.1$ & $11.6 \pm 0.2$ & $10.2 \pm 0.8$ & $10.0 \pm 1.8$ & $11.3 \pm 1.3$ & $10.1 \pm 1.7$ & $10.6 \pm 0.6$ & $9.4 \pm 0.8$ & $10.2 \pm 1.0$ & $11.1 \pm 1.5$ \\
\hline $22: 5 n-6$ & $3.1 \pm 0.5$ & $\begin{array}{l}2.4 \pm 0.3 \\
3.8 \pm 0.6\end{array}$ & $\begin{array}{l}2.2 \pm 0.2 \\
3.4 \pm 0.6\end{array}$ & & $3.1 \pm 0.5$ & $2.6 \pm 0.6$ & $3.2 \pm 0.3$ & $3.4 \pm 0.2$ & $\begin{array}{r}3.4 \pm 0.2 \\
11.6 \pm 0.7\end{array}$ & $\begin{array}{l}2.8 \pm 0.2 \\
8.3 \pm 0.1\end{array}$ & $\begin{array}{l}2.9 \pm 0.3 \\
7.4 \pm 1.3 \dagger\end{array}$ & $\begin{array}{r}3.2 \pm 0.7 \\
102+15\end{array}$ & $2.9 \pm 0.5$ & $\begin{array}{l}3.4 \pm 0.1 \\
66 \pm 20\end{array}$ & $\begin{array}{l}2.8 \pm 0.7 \\
9.4 \pm 2.0\end{array}$ & $\begin{array}{l}2.6 \pm 0.7 \\
8.1 \pm 2.3\end{array}$ & $\begin{array}{l}3.1 \pm 0.4 \\
5.0 \pm 1.1\end{array}$ \\
\hline Total $n-6$ & $16.9 \pm 1.9$ & $\begin{array}{r}3.8 \pm 0.0 \\
16.5 \pm 1.6\end{array}$ & $\begin{array}{r}3.4 \pm 0.0 \\
15.8 \pm 1.1\end{array}$ & $\begin{array}{r}4.4 \pm 0.2 \\
18.2 \pm 0.5\end{array}$ & $\begin{array}{l}12.4 \pm 2.5 \\
28.8 \pm 4.3\end{array}$ & $\begin{array}{l}10.6 \pm 2.1 \\
24.6 \pm 3.9\end{array}$ & $\begin{array}{l}11.6 \pm 0.9 \\
28.2 \pm 3.0\end{array}$ & $\begin{array}{r}9.8 \pm 1.2 \\
27.0 \pm 2.0\end{array}$ & $\begin{array}{l}11.6 \pm 0.7 \\
28.5 \pm 1.2\end{array}$ & $\begin{array}{r}8.3 \pm 0.1 \\
23.2 \pm 1.1\end{array}$ & $\begin{aligned} 7.4 & \pm 1.3 \dagger \\
22.0 & \pm 3.3\end{aligned}$ & $\begin{array}{l}10.2 \pm 1.5 \\
25.5 \pm 3.5\end{array}$ & $\begin{array}{r}7.1 \pm 1.6 \\
20.4 \pm 5.2\end{array}$ & $\begin{array}{r}6.6 \pm 2.0 \\
21.7 \pm 1.8\end{array}$ & $\begin{array}{r}9.4 \pm 2.0 \\
23.7 \pm 2.9\end{array}$ & $\begin{array}{r}8.1 \pm 2.3 \\
21.0 \pm 5.6\end{array}$ & $\begin{array}{r}5.0 \pm 1.1 \\
20.4 \pm 2.6\end{array}$ \\
\hline $18: 3 n-3$ & & & & & & & & & $0.2 \pm 0.1$ & $0.1 \pm 0.0$ & $0.1 \pm 0.1$ & & & & & & \\
\hline $\begin{array}{l}20: 5 n-3 \\
22: 5 n-3\end{array}$ & $0.4 \pm 0.1$ & $0.2 \pm 0.1$ & & $0.2 \pm 0.1$ & & & & & & $0.1 \pm 0.1$ & $0.1 \pm 0.1$ & $0.1 \pm 0.0$ & $0.2 \pm 0.1$ & $0.1 \pm 0.1$ & & & \\
\hline $22: 6 n-3$ & $10.5 \pm 2.5$ & $8.5 \pm 0.9$ & $8.3 \pm 1.7$ & $8.3 \pm 0.4$ & $1.8 \pm 0.5$ & $0.6 \pm 0.2$ & $0.9 \pm 0.6$ & $0.8 \pm 0.3$ & $\begin{array}{l}0.1 \pm 0.1 \\
0.7 \pm 0.0 \ddagger\end{array}$ & $\begin{array}{l}0.7 \pm 0.1 \\
1.8 \pm 0.4 \ddagger\end{array}$ & $\begin{array}{l}0.8 \pm 0.3 \\
3.5 \pm 0.7 \ddagger\end{array}$ & $\begin{array}{l}0.4 \pm 0.1 \\
2.0 \pm 0.3\end{array}$ & $\begin{array}{l}1.0 \pm 0.4 \\
5.9 \pm 1.1\end{array}$ & $\begin{array}{l}1.3 \pm 0.0 \\
9.8 \pm 3.3\end{array}$ & $\begin{array}{l}0.1 \pm 0.1 \\
2.2 \pm 0.6\end{array}$ & $5.8 \pm 1.6$ & \\
\hline Total $n-3$ & $10.7 \pm 1.5$ & $8.8 \pm 0.9$ & $8.6 \pm 1.4$ & $8.5 \pm 0.4$ & $1.8 \pm 0.5$ & $0.6 \pm 0.2$ & $0.9 \pm 0.6$ & $0.8 \pm 0.3$ & $0.9 \pm 0.1 \ddagger$ & $2.7 \pm 0.47$ & $4.3 \pm 0.9 \ddagger$ & $2.5 \pm 0.2$ & $7.1 \pm 1.1$ & $\begin{array}{r}10.8 \pm 2.8 \\
10.8 \pm 2.8\end{array}$ & $\begin{array}{l}2.2 \pm 0.0 \\
2.5 \pm 0.7\end{array}$ & $\begin{array}{l}5.8 \pm 1.0 \\
5.8 \pm 1.6\end{array}$ & $12.9 \pm 3.2$ \\
\hline$n$ & 3 & 3 & 3 & 3 & 3 & 3 & 3 & 3 & 3 & 3 & 4 & 3 & 5 & 3 & 4 & 4 & 5 \\
\hline
\end{tabular}


Table 4. Retinal fatty acid composition (wt\%) after refeeding of $n$-3-deficient chicks with 18:3, 20:5, or 22:6 for 1, 2, and 3 wk

\begin{tabular}{|c|c|c|c|c|c|c|c|c|c|c|c|c|c|c|c|c|c|}
\hline & \multicolumn{4}{|c|}{ Control diet } & \multicolumn{4}{|c|}{ Deficient diet* } & \multicolumn{3}{|c|}{ Deficient diet $+18: 3$} & \multicolumn{3}{|c|}{ Deficient diet $+20: 5$} & \multicolumn{3}{|c|}{ Deficient $+22: 6$} \\
\hline & \multicolumn{4}{|c|}{ Wk } & \multicolumn{4}{|c|}{$\mathrm{Wk}$} & \multicolumn{3}{|c|}{$\mathrm{Wk}$} & \multicolumn{3}{|c|}{ Wk } & \multicolumn{3}{|c|}{ Wk } \\
\hline & 0 & 1 & 2 & 3 & 0 & 1 & 2 & 3 & 1 & 2 & 3 & 1 & 2 & 3 & 1 & 2 & 3 \\
\hline $16: 0$ & $28.6 \pm 3.1$ & $29.1 \pm 5.3$ & $30.6 \pm 1.0$ & $21.8 \pm 3.1$ & $33.3 \pm 0.1$ & $33.2 \pm 2.4$ & $29.5 \pm 3.3$ & $25.6 \pm 2.3$ & $26.6 \pm 2.8$ & $30.3 \pm 3.5$ & $29.8 \pm 2.9$ & $24.4 \pm 6.2$ & $23.5 \pm 6.1$ & $27.0 \pm 3.7$ & $26.0 \pm 4.0$ & $24.2 \pm 1.8$ & $25.8 \pm 4.1$ \\
\hline 18:0 & $20.2 \pm 1.9$ & $23.2 \pm 1.0$ & $23.1 \pm 0.9$ & $24.0 \pm 2.7$ & $22.7 \pm 5.9$ & $20.4 \pm 0.2$ & $21.4 \pm 1.3$ & $26.2 \pm 1.1$ & $19.9 \pm 6.2$ & $21.2 \pm 0.6$ & $21.2 \pm 1.2$ & $25.4 \pm 1.2$ & $26.8 \pm 9.5$ & $22.6 \pm 3.7$ & $19.7 \pm 0.9$ & $21.9 \pm 1.5$ & $20.3 \pm 0.7$ \\
\hline Total sat. & $52.3 \pm 3.6$ & $53.7 \pm 6.5$ & $55.6 \pm 0.3$ & $46.3 \pm 6.5$ & $55.9 \pm 0.5$ & $56.1 \pm 3.0$ & $53.9 \pm 3.9$ & $52.4 \pm 1.5$ & $47.4 \pm 4.3$ & $53.0 \pm 3.5$ & $54.0 \pm 2.7$ & $52.7 \pm 7.9$ & $54.1 \pm 9.6$ & $52.2 \pm 3.4$ & $50.8 \pm 5.9$ & $49.1 \pm 2.5$ & $48.0 \pm 4.5$ \\
\hline $16: \ln -7$ & $2.8 \pm 0.8$ & $2.9 \pm 1.0$ & $2.4 \pm 0.7$ & $1.8 \pm 0.2$ & $3.9 \pm 0.5$ & $3.5 \pm 0.5$ & $3.2 \pm 0.6$ & $1.4 \pm 0.1$ & $3.7 \pm 2.2$ & $2.6 \pm 0.8$ & $3.1 \pm 0.4$ & $1.6 \pm 0.3$ & $2.0 \pm 1.6$ & $2.6 \pm 1.1$ & $2.6 \pm 0.2$ & $2.1 \pm 0.3$ & $2.4 \pm 0.9$ \\
\hline $18: 1 \mathrm{n}-9$ & $13.5 \pm 1.4$ & $15.8 \pm 0.6$ & $15.6 \pm 0.2$ & $18.3 \pm 2.4$ & $14.2 \pm 0.6$ & $16.2 \pm 2.0$ & $15.7 \pm 1.7$ & $15.4 \pm 0.4$ & $20.3 \pm 8.9$ & $15.1 \pm 0.9$ & $14.5 \pm 1.5$ & $16.2 \pm 2.5$ & $15.0 \pm 2.4$ & $13.5 \pm 0.5$ & $15.1 \pm 1.6$ & $15.5 \pm 1.1$ & $14.4 \pm 1.0$ \\
\hline Total mono. & $16.9 \pm 2.0$ & $19.3 \pm 1.3$ & $18.8 \pm 0.3$ & $20.6 \pm 2.2$ & $18.5 \pm 0.8$ & $20.3 \pm 1.5$ & $19.5 \pm 2.3$ & $17.7 \pm 0.5$ & $24.6 \pm 11.2$ & $18.2 \pm 0.9$ & $18.3 \pm 1.8$ & $18.0 \pm 3.0$ & $17.8 \pm 3.5$ & $16.6 \pm 1.1$ & $23.6 \pm 4.7$ & $18.4 \pm 0.8$ & $17.3 \pm 1.8$ \\
\hline $20: 3 n-9$ & $0.1 \pm 0.1$ & $0.4 \pm 0.3$ & $0.2 \pm 0.2$ & $0.1 \pm 0.2$ & $0.1 \pm 0.1$ & $0.3 \pm 0.1$ & $0.1 \pm 0.2$ & $0.3 \pm 0.1$ & $0.2 \pm 0.0$ & $0.2 \pm 0.0$ & $0.1 \pm 0.1$ & $0.1 \pm 0.1$ & $0.0 \pm 0.0$ & $0.1 \pm 0.1$ & $0.1 \pm 0.0$ & $0.1 \pm 0.1$ & $0.1 \pm 0.1$ \\
\hline $18: 2 \mathrm{n}-6$ & $2.2 \pm 1.9$ & $0.8 \pm 0.1$ & $1.4 \pm 0.2$ & $2.6 \pm 0.6$ & $1.6 \pm 0.3$ & $1.7 \pm 0.6$ & $1.6 \pm 0.3$ & $0.8 \pm 0.1$ & $3.2 \pm 3.5$ & $1.1 \pm 0.5$ & $1.0 \pm 0.2$ & $2.4 \pm 2.1$ & $1.2 \pm 0.6$ & $0.9 \pm 0.2$ & $4.6 \pm 3.4$ & $4.4 \pm 3.4$ & $3.3 \pm 3.4$ \\
\hline $20: 4 n-6$ & $9.3 \pm 1.9$ & $9.5 \pm 2.8$ & $8.8 \pm 1.0$ & $9.4 \pm 0.2$ & $8.2 \pm 0.8$ & $7.9 \pm 0.2$ & $8.2 \pm 0.1$ & $10.1 \pm 0.3$ & $7.9 \pm 3.2$ & $8.6 \pm 1.7$ & $8.2 \pm 1.1$ & $9.7 \pm 1.4$ & $8.6 \pm 3.2$ & $9.8 \pm 2.1$ & $7.0 \pm 1.0$ & $7.7 \pm 1.1$ & $7.7 \pm 2.2$ \\
\hline $22: 4 n-6$ & $1.8 \pm 0.6$ & $1.5 \pm 0.2$ & $2.0 \pm 0.5$ & $2.4 \pm 0.2$ & $2.5 \pm 0.2$ & $1.9 \pm 1.1$ & $2.9 \pm 0.5$ & $3.0 \pm 0.1$ & $2.9 \pm 1.3$ & $3.3 \pm 0.5$ & $2.8 \pm 0.6$ & $2.8 \pm 0.8$ & $2.4 \pm 0.8$ & $2.9 \pm 0.5$ & $2.6 \pm 0.6$ & $2.9 \pm 0.3$ & $2.3 \pm 0.7$ \\
\hline $22: 5 n-6$ & $3.5 \pm 1.3$ & $4.4 \pm 2.3$ & $4.7 \pm 0.6$ & $4.8 \pm 2.2$ & $10.2 \pm 0.4$ & $11.3 \pm 1.4$ & $11.5 \pm 1.2$ & $12.7 \pm 0.5$ & $12.0 \pm 6.0$ & $11.7 \pm 1.6$ & $9.8 \pm 1.6$ & $12.4 \pm 4.7$ & $9.0 \pm 3.4$ & $5.7 \pm 2.4$ & $9.9 \pm 1.2$ & $9.6 \pm 1.9$ & $5.8 \pm 2.4$ \\
\hline Total n-6 & $16.9 \pm 2.2$ & $16.4 \pm 4.7$ & $15.4 \pm 1.1$ & $20.4 \pm 2.9$ & $23.1 \pm 1.3$ & $22.8 \pm 2.3$ & $24.8 \pm 2.1$ & $27.3 \pm 0.7$ & $26.9 \pm 7.3$ & $25.6 \pm 3.3$ & $22.8 \pm 2.5$ & $27.2 \pm 8.5$ & $21.7 \pm 7.8$ & $20.0 \pm 3.6$ & $24.7 \pm 5.4$ & $25.6 \pm 2.5$ & $19.9 \pm 3.0$ \\
\hline $\begin{array}{l}18: 3 n-3 \\
20: 5 n-3\end{array}$ & & & & & & & & & $0.2 \pm 0.3$ & $0.1 \pm 0.0$ & $0.1 \pm 0.1$ & $0.4 \pm 0.3$ & $0.1 \pm 0.1$ & $\begin{array}{l}0.0 \pm 0.0 \\
0.0 \pm 0.1\end{array}$ & & $0.2 \pm 0.1$ & $\begin{array}{l}0.2 \pm 0.2 \\
0.2 \pm 0.2\end{array}$ \\
\hline $22: 5 n-3$ & & & & & & & & & $0.1 \pm 0.1$ & $0.4 \pm 0.1$ & $0.5 \pm 0.1$ & $0.2 \pm 0.2$ & $0.6 \pm 0.3$ & $0.4 \pm 0.2$ & $0.1 \pm 0.2$ & $0.1 \pm 0.1$ & $0.3 \pm 0.2$ \\
\hline $22: 6 n-3$ & $12.9 \pm 3.3$ & $9.6 \pm 2.6$ & $7.5 \pm 2.6$ & $12.3 \pm 2.2$ & $1.6 \pm 0.0$ & $0.5 \pm 0.3$ & $0.8 \pm 0.3$ & $1.2 \pm 0.8$ & $0.6 \pm 0.3 \dagger$ & $2.1 \pm 0.6 \dagger$ & $3.8 \pm 0.6 \dagger$ & $1.9 \pm 0.9$ & $4.7 \pm 1.7$ & $10.7 \pm 2.6$ & $2.9 \pm 0.8$ & $5.4 \pm 0.4$ & $11.2 \pm 3.1$ \\
\hline Total n-3 & $12.9 \pm 3.3$ & $9.7 \pm 2.5$ & $7.5 \pm 2.6$ & $12.3 \pm 2.2$ & $1.8 \pm 0.3$ & $0.5 \pm 0.3$ & $0.8 \pm 0.3$ & $1.2 \pm 0.8$ & $0.8 \pm 0.1 \ddagger$ & $2.6 \pm 0.7 \ddagger$ & $4.5 \pm 0.7 \ddagger$ & $2.2 \pm 0.7$ & $5.3 \pm 2.0$ & $11.2 \pm 2.4$ & $2.9 \pm 0.9$ & $5.9 \pm 0.4$ & $11.7 \pm 3.2$ \\
\hline$n$ & 3 & 3 & 3 & 3 & 3 & 3 & 3 & 3 & 3 & 3 & 4 & 3 & 5 & 3 & 4 & 4 & 5 \\
\hline
\end{tabular}

* The zero time point applies also to the three repletion diets.

Different from respective time points for 20:5 and 22:6 diets, $p=0.015$ 


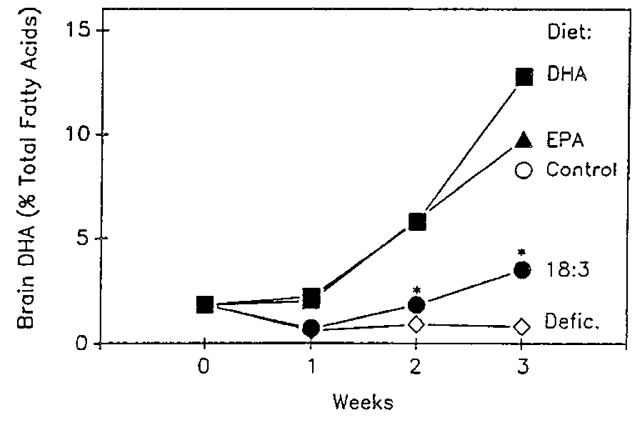

Fig. 1. Repletion of brain DHA after the refeeding of n-3-deficient chicks with 18:3, EPA, or DHA (*different from the other two repletion diets at $p<0.001$ ).

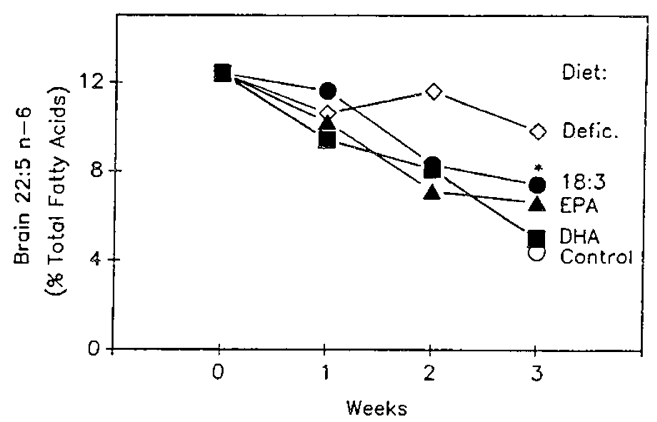

Fig. 2. Decrease in brain 22:5n-6 after the refeeding of n-3-deficient chicks with 18:3, EPA, or DHA (*different from the other two repletion diets at $p=0.045$ ).

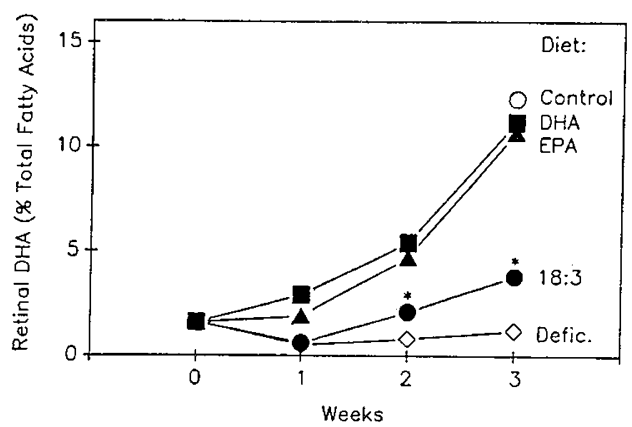

Fig. 3. Repletion of retinal DHA after the refeeding of n-3-deficient chicks with 18:3, EPA, or DHA (*different from the other two repletion diets at $p=0.015$ ).

relatively large amount of EPA that was present in the serum of DHA-fed chicks at $3 \mathrm{wk}$ of age. A small amount of 22:5n-3, an intermediate between DHA and EPA, was also detectable.

A similar fatty acid pattern was seen in the livers of the repleted chicks (Table 6). The amount of DHA formed from EPA was especially low at wk $1-2$, relative to the amount of DHA that accumulated when DHA was fed directly. Not until wk 3 was any significant synthesis of DHA from dietary EPA apparent in the liver. The amount of DHA in the livers of chicks fed 18:3 was quire low at 3 wk, relative to the chicks fed EPA, and was comparable to levels reported by Rogel and Watkins (19) in the livers of 3-wk-old chicks fed a similar diet. The changes in serum and liver DHA levels are shown graphically in Figures 4-5.

\section{DISCUSSION}

Only the very long-chain and highly polyunsaturated fatty acids, DHA and EPA, provided prompt correction of the n-3deficient state in the brain and retina of the chick. This correction was complete after 3 wk of feeding. Linolenic acid (18:3n-3) did not correct at all for 2 wk of feeding and only minimally after 3 wk. The slow recovery of nervous tissue DHA levels in n-3 fatty acid deficient rats refed with 18:3 has also been noted by Bourre and coworkers (20-23), who found that complete recovery took $2 \frac{1}{2}$ to 3 mo in rats. One possible explanation for the slow recovery with dietary 18:3, as compared with EPA and DHA, could be the fact that $18: 3$ is positioned before the rate limiting step in the formation of $22: 6$, namely the $\delta-6$ desaturation of $18: 3$ to 18:4. However, we think this is not the best explanation, because serum levels of total n-3 fatty acids in our chicks fed 18:3 were much lower than in chicks fed EPA or DHA. This observation would argue that there was a partial diversion of 18:3 to oxidative pathways. In this regard, Leyton et al. (24) found that dietary $18: 3 n-3$ was oxidized in rats to a greater extent than other unsaturated fatty acids. This relative selectivity against $18: 3 n-3$ is probably due to the position of the terminal double bond, and not to a special susceptibility of 18 carbon trienoic fatty acids, because $18: 3 n-6$ was oxidized to far lesser extent than $18: 3 n-3$ (24).

Nevertheless, the chicks in our study were able to desaturate $18: 3 n-3$ to some extent, as evidenced by the fact that most of the $\mathrm{n}-3$ fatty acids in the serum of 18:3-fed chicks were present as desaturation-elongation products of 18:3. Other animals, for instance, rats and monkeys, are also able to use 18:3 to produce DHA $(16,20,25,26)$.

Dietary 18:3 might be expected to be an even less efficient precursor for DHA in animals with low $\delta-6$ desaturase activity. In this light, there is doubt about the ability of the adult human to desaturate and elongate $18: 3 n-3$ and EPA to any appreciable extent (27-29). Even vegans, whose plasma is low in DHA, were not able to increase levels of DHA when fed a diet containing large amounts of $18: 3 n-3$ for $3 \mathrm{wk}(30)$. Thus, it is possible that the human organism could have an even stronger preference than the chick for dietary DHA over dietary 18:3 as the ultimate source of tissue DHA.

This has possible implications for infant feeding practices. Human milk contains both 18:3 and DHA as the "natural" source of n-3 fatty acids for the developing infant. It does not contain any EPA. However, infant formulas have 18:3 as the only source of the n-3 essential fatty acids. They contain no DHA or EPA. Some infant formulas have little 18:3 and a high $\mathrm{n}-6 / \mathrm{n}-3$ ratio which has produced $\mathrm{n}-3$ fatty acid deficiency in monkeys, both biochemically and clinically (4). Our results in chicks with brain and tissue fatty acid composition correlate very well with the blood findings of Carlson et al. $(31,32)$ in human infants. They determined that formula feeding produces a less than optimal concentration of DHA in erythrocyte membranes as compared with human milk or formula supplemented with EPA and DHA. DHA is apparently so important for development that a laying hen fed an n-3 fatty acid-deficient diet for many months (9) still passed DHA to the chick (through the yolk) at a quantity similar to that found in human milk, namely $0.2 \%$ of fatty acids. There are no tissue data from human infants comparable to the data from chicks presented in our report.

The near equivalence of dietary EPA and DHA in restoring levels of DHA in the brain and retina of n-3 fatty acid chicks was unexpected. It has been suggested that the brain receives much of its complement of DHA "preformed" from the circulation via the liver $(33,34)$, although the rat brain, and especially the developing rat brain, has a substantial capacity for the synthesis of DHA from precursor molecules $(35,36)$. Our results showed that DHA was formed from dietary EPA and accumulated in the brain to nearly the same extent as the DHA when fed directly in the diet. This occurred despite the lower level of 
Table 5. Serum fatty acid composition (wt\%) after refeeding of $n$-3-deficient chicks with 18:3, 20:5, or 22:6 for 1, 2 and 3 wk

\begin{tabular}{|c|c|c|c|c|c|c|c|c|c|c|c|c|c|c|c|c|c|}
\hline & \multicolumn{4}{|c|}{ Control diet } & \multicolumn{4}{|c|}{ Deficient diet* } & \multicolumn{3}{|c|}{ Deficient diet $+18: 3$} & \multicolumn{3}{|c|}{ Deficient diet $+20: 5$} & \multicolumn{3}{|c|}{ Deficient diet $+22: 6$} \\
\hline & \multicolumn{4}{|c|}{ Wk } & \multicolumn{4}{|c|}{ Wk } & \multicolumn{3}{|c|}{ Wk } & \multicolumn{3}{|c|}{ Wk } & \multicolumn{3}{|c|}{ Wk } \\
\hline & 0 & 1 & 2 & 3 & 0 & 1 & 2 & 3 & 1 & 2 & 3 & 1 & 2 & 3 & 1 & 2 & 3 \\
\hline $16: 0$ & $24.1 \pm 3.4$ & $30.6 \pm 2.4$ & $23.6 \pm 5.0$ & $25.0 \pm 1.3$ & $22.9 \pm 2.4$ & $25.5 \pm 2.8$ & $23.1 \pm 1.1$ & $23.4 \pm 3.0$ & $26.0 \pm 2.8$ & $25.2 \pm 0.6$ & $23.6 \pm 4.9$ & $26.3 \pm 1.3$ & $24.1 \pm 4.0$ & $25.3 \pm 1.3$ & $25.9 \pm 4.2$ & $28.4 \pm 0.6$ & $22.5 \pm 2.0$ \\
\hline $18: 0$ & $11.3 \pm 0.4$ & $12.3 \pm 1.0$ & $14.8 \pm 0.7$ & $14.2 \pm 1.4$ & $12.1 \pm 0.6$ & $13.4 \pm 1.0$ & $15.5 \pm 1.4$ & $15.9 \pm 1.0$ & $8.9 \pm 1.1$ & $16.6 \pm 0.7$ & $16.2 \pm 1.0$ & $11.1 \pm 1.8$ & $16.0 \pm 0.4$ & $16.5 \pm 0.7$ & $14.4 \pm 3.0$ & $15.4 \pm 0.3$ & $17.1 \pm 1.0$ \\
\hline Total sat. & $36.2 \pm 3.3$ & $43.8 \pm 2.1$ & $39.2 \pm 4.9$ & $39.7 \pm 0.5$ & $37.8 \pm 2.2$ & $44.1 \pm 2.5$ & $41.8 \pm 3.1$ & $41.3 \pm 3.2$ & $37.3 \pm 2.1$ & $43.3 \pm 1.5$ & $40.5 \pm 3.4$ & $38.7 \pm 2.6$ & $42.9 \pm 5.4$ & $45.3 \pm 2.0$ & $43.7 \pm 2.6$ & $48.3 \pm 0.8$ & $42.3 \pm 3.1$ \\
\hline $16: 1 \mathrm{n}-7$ & $1.6 \pm 0.5$ & $3.8 \pm 0.8$ & $2.2 \pm 0.5$ & $2.5 \pm 0.2$ & $1.6 \pm 0.3$ & $4.4 \pm 1.4$ & $3.9 \pm 0.8$ & $3.5 \pm 0.4$ & $7.9 \pm 0.7$ & $3.6 \pm 0.6$ & $2.7 \pm 0.6$ & $5.5 \pm 0.8$ & $3.8 \pm 0.5$ & $3.0 \pm 0.4$ & $4.5 \pm 1.3$ & $3.8 \pm 0.3$ & $2.6 \pm 0.3$ \\
\hline $18: 1 n-9$ & $26.2 \pm 1.1$ & $27.8 \pm 1.5$ & $30.3 \pm 4.2$ & $28.7 \pm 0.6$ & $22.6 \pm 1.4$ & $23.3 \pm 1.8$ & $27.3 \pm 2.6$ & $26.4 \pm 4.1$ & $29.8 \pm 0.6$ & $27.0 \pm 2.0$ & $24.5 \pm 1.0$ & $26.4 \pm 0.5$ & $25.3 \pm 2.8$ & $19.3 \pm 2.2$ & $22.3 \pm 1.3$ & $19.8 \pm 1.9$ & $21.5 \pm 2.3$ \\
\hline Total mono. & $28.0 \pm 1.2$ & $35.2 \pm 7.9$ & $33.9 \pm 4.2$ & $31.7 \pm 0.6$ & $24.7 \pm 1.3$ & $28.3 \pm 1.9$ & $31.6 \pm 3.4$ & $30.4 \pm 4.6$ & $37.9 \pm 0.7$ & $30.9 \pm 2.5$ & $27.6 \pm 1.5$ & $32.1 \pm 0.9$ & $29.6 \pm 3.1$ & $22.4 \pm 1.9$ & $27.1 \pm 2.6$ & $24.3 \pm 2.2$ & $26.0 \pm 2.8$ \\
\hline $20: 3 n-9$ & $0.2 \pm 0.0$ & $0.7 \pm 0.2$ & $1.9 \pm 0.6$ & $1.4 \pm 0.3$ & $0.2 \pm 0.0$ & $1.2 \pm 0.5$ & $1.0 \pm 0.1$ & $0.9 \pm 0.2$ & $0.8 \pm 0.2$ & $1.0 \pm 0.1$ & $0.8 \pm 0.2$ & $0.6 \pm 0.2$ & $0.7 \pm 0.1$ & $0.6 \pm 0.2$ & $0.7 \pm 0.2$ & $0.7 \pm 0.1$ & $0.8 \pm 0.2$ \\
\hline & $24.4 \pm 2.2$ & $16.1 \pm 1.6$ & $14.6 \pm 1.2$ & $15.1 \pm 0.6$ & $22.5 \pm 1.2$ & $16.5 \pm 1.1$ & $14.8 \pm 0.9$ & $17.1 \pm 2.4$ & $15.0 \pm 1.2$ & $14.6 \pm 0.5$ & $17.0 \pm 2.6$ & $15.3 \pm 1.0$ & $13.0 \pm 0.7$ & $15.1 \pm 0.9$ & 14.8 & $14.4=$ & $15.7 \pm 0.7$ \\
\hline $20: 4 r$ & $8.7 \pm 2.6$ & $3.8 \pm 1.1$ & $6.9 \pm 0.4$ & $7.2 \pm 0.8$ & $9.7 \pm 0.8$ & $5.8 \pm 1.0$ & $7.4 \pm 3.0$ & $6.4 \pm 3.1$ & $4.6 \pm 0.8$ & $4.8 \pm 1.1$ & $6.9 \pm 1.2$ & $6.2 \pm 0.8$ & $5.3 \pm 0.2$ & $7.2 \pm 0.3$ & & $6.4 \pm 0.4$ & $6.8 \pm 1.8$ \\
\hline $22: 4 n$ & $0.4 \pm 0.1$ & $0.2 \pm 0.1$ & $0.3 \pm 0.1$ & $0.4 \pm 0.1$ & $0.6 \pm 0.2$ & $0.4 \pm 0.1$ & $0.3 \pm 0.2$ & $0.4 \pm 0.3$ & $0.3 \pm 0.0$ & $0.2 \pm 0.1$ & $0.4 \pm 0.1$ & $0.4 \pm 0.1$ & $0.2 \pm 0.1$ & $0.2 \pm 0.3$ & $0.7 \pm 0.3$ & $0.5 \pm 0.3$ & $0.3 \pm 0.1$ \\
\hline $22: 5 n-6$ & $0.6 \pm 0.5$ & $0.4 \pm 0.1$ & $0.4 \pm 0.2$ & $0.5 \pm 0.1$ & $2.8 \pm 0.5$ & $1.6 \pm 0.4$ & $0.8 \pm 0.2$ & $0.7 \pm 0.4$ & & $1.4 \pm 0.1$ & $0.5 \pm 0.1$ & $0.8 \pm 0.2$ & $0.2 \pm 0.1$ & $0.3 \pm 0.3$ & $0.9 \pm 0.2$ & $0.9 \pm 0.3$ & $0.2 \pm 0.1$ \\
\hline Total n-6 & $33.8 \pm 3.3$ & $21.9 \pm 2.9$ & $24.3 \pm 1.5$ & $25.3 \pm 0.2$ & $35.6 \pm 1.3$ & $25.9 \pm 3.1$ & $25.3 \pm 2.5$ & $26.7 \pm 5.9$ & $22.9 \pm 2.2$ & $22.2 \pm 1.4$ & $27.5 \pm 3.1$ & $24.2 \pm 0.7$ & $20.3 \pm 1.0$ & $24.4 \pm 0.5$ & $24.6 \pm 3.6$ & $22.9 \pm 2.8$ & $25.0 \pm 2.1$ \\
\hline $18: 3 n-3$ & 0.0 & $4 \pm 0.0$ & \pm 0.0 & & & & & & & & & & & & & & \\
\hline & .1 & $0.2 \pm 0.0$ & \pm 0 & 0 & & & & & & $0.5 \pm 0$ & $0.7 \pm 0.1$ & $3.4 \pm 0.8$ & $4.4 \pm 1.4$ & $4.4 \pm 1.2$ & $0.6 \pm 0.2$ & $0.8 \pm 0.2$ & $1.8 \pm 0.2$ \\
\hline $22: 5 n-$ & $0.1 \pm 0.0$ & $0.1 \pm 0.1$ & $0.3 \pm 0.3$ & $0.2 \pm 0.2$ & & & & & & $0.4 \pm 0$ & & $0.3 \pm 0.1$ & $0.7 \pm 0.3$ & $0.9 \pm 0.3$ & & & $0.2 \pm 0.1$ \\
\hline $22: 6 n-3$ & $1.2 \pm 0.5$ & $0.5 \pm 0.2$ & $0.8 \pm 0.1$ & $1.2 \pm 0.2$ & $0.2 \pm 0.0$ & & & & $0.3 \pm 0.2 \dagger$ & $0.8 \pm 0.2 \dagger$ & $1.7 \pm 0.0 \dagger \ddagger$ & $0.6 \pm 0.3$ & $1.5 \pm 0.7$ & $3.0 \pm 0.6$ & $3.6 \pm 1.6 \ddagger$ & $3.8 \pm 0.7 \ddagger$ & $5.7 \pm 0.9 \ddagger$ \\
\hline Total $n-3$ & $1.6 \pm 0.6$ & $1.1 \pm 0.2$ & $1.5 \pm 0.1$ & $1.9 \pm 0.4$ & $0.2 \pm 0.0$ & & & & $1.5 \pm 0.2 \S$ & $2.3 \pm 0.1 \S$ & $3.4 \pm 0.18$ & $4.3 \pm 1.1$ & $6.1 \pm 1.3$ & $7.7 \pm 1.3$ & $4.2 \pm 1.6^{\circ}$ & $4.6 \pm 0.9^{\circ}$ & $7.7 \pm 0.8$ \\
\hline$n$ & 3 & 3 & 3 & 3 & 3 & 3 & 3 & 3 & 3 & 3 & 4 & 3 & 4 & 3 & 4 & 3 & 5 \\
\hline
\end{tabular}

${ }^{*}$ The zero time point applies also to the three repletion diets.

Different from respective time points for $22: 6$ diet, $p=0.02$

Different from respective time points for 20:5 and 22:6 diets, $p<0.001$ 
Table 6. Liver fatty acid composition (wt\%) after refeeding of n-3-deficient chicks with 18:3, 20:5, or 22:6 for 1,2, and 3 wk

\begin{tabular}{|c|c|c|c|c|c|c|c|c|c|}
\hline & \multicolumn{3}{|c|}{ Deficient $+18: 3$} & \multicolumn{3}{|c|}{ Deficient $+20: 5$} & \multicolumn{3}{|c|}{ Deficient $+22: 6$} \\
\hline & \multicolumn{3}{|c|}{ Wk } & \multicolumn{3}{|c|}{ Wk } & \multicolumn{3}{|c|}{ Wk } \\
\hline & 1 & 2 & 3 & 1 & 2 & 3 & 1 & 2 & 3 \\
\hline $16: 0$ & $33.3 \pm 3.4$ & $28.1 \pm 3.8$ & $25.9 \pm 1.9$ & $34.9 \pm 6.6$ & $32.6 \pm 1.1$ & $24.5 \pm 2.9$ & $30.9 \pm 6.5$ & $30.3 \pm 5.5$ & $24.2 \pm 3.7$ \\
\hline $18: 0$ & $7.1 \pm 0.7$ & $13.6 \pm 1.8$ & $14.2 \pm 3.1$ & $8.7 \pm 0.9$ & $11.0 \pm 0.8$ & $17.1 \pm 0.9$ & $11.5 \pm 5.8$ & $14.0 \pm 2.2$ & $14.6 \pm 2.7$ \\
\hline Total sat. & $42.1 \pm 3.0$ & $44.0 \pm 3.0$ & $42.1 \pm 3.7$ & $46.0 \pm 8.3$ & $45.3 \pm 2.7$ & $42.5 \pm 2.8$ & $43.5 \pm 4.9$ & $45.1 \pm 6.5$ & $39.6 \pm 4.3$ \\
\hline $16: 1 n-7$ & $11.0 \pm 1.5$ & $5.4 \pm 1.1$ & $4.6 \pm 1.5$ & $7.7 \pm 1.7$ & $6.7 \pm 0.8$ & $3.2 \pm 0.5$ & $6.5 \pm 2.6$ & $4.3 \pm 1.0$ & $3.7 \pm 1.6$ \\
\hline $18: 1 \mathrm{n}-9$ & $37.5 \pm 2.4$ & $34.4 \pm 4.1$ & $30.9 \pm 4.4$ & $37.7 \pm 6.1$ & $32.5 \pm 3.7$ & $24.6 \pm 2.7$ & $35.3 \pm 6.9$ & $31.0 \pm 4.0$ & $27.6 \pm 4.4$ \\
\hline Total mono. & $49.3 \pm 0.7$ & $40.5 \pm 5.2$ & $35.9 \pm 4.4$ & $46.1 \pm 5.3$ & $39.9 \pm 4.4$ & $28.4 \pm 3.0$ & $42.4 \pm 9.1$ & $35.7 \pm 4.2$ & $31.7 \pm 5.5$ \\
\hline $20: 3 n-9$ & $0.2 \pm 0.0$ & $0.5 \pm 0.2$ & $0.7 \pm 0.4$ & $0.2 \pm 0.0$ & $0.4 \pm 0.1$ & $0.7 \pm 0.2$ & $0.3 \pm 0.1$ & $0.5 \pm 0.2$ & $0.5 \pm 0.1$ \\
\hline $18: 2 n-6$ & $4.3 \pm 0.7$ & $6.9 \pm 2.7$ & $9.5 \pm 0.7$ & $3.9 \pm 1.2$ & $5.5 \pm 0.8$ & $9.0 \pm 0.7$ & $5.8 \pm 2.7$ & $7.6 \pm 0.3$ & $10.0 \pm 1.5$ \\
\hline $20: 4 n-6$ & $2.5 \pm 1.1$ & $4.5 \pm 2.2$ & $6.6 \pm 1.1$ & $2.4 \pm 0.7$ & $3.6 \pm 0.8$ & $8.8 \pm 0.6$ & $4.0 \pm 2.6$ & $5.4 \pm 1.2$ & $7.6 \pm 1.9$ \\
\hline $22: 4 n-6$ & $0.2 \pm 0.1$ & $0.3 \pm 0.1$ & $0.2 \pm 0.1$ & $0.1 \pm 0.0$ & $0.2 \pm 0.1$ & $0.4 \pm 0.5$ & $0.3 \pm 0.1$ & $0.0 \pm 0.0$ & $0.3 \pm 0.2$ \\
\hline $22: 5 n-6$ & $0.4 \pm 0.4$ & $0.3 \pm 0.2$ & $0.3 \pm 0.1$ & $0.5 \pm 0.2$ & $0.2 \pm 0.1$ & $0.4 \pm 0.3$ & $0.6 \pm 0.4$ & $0.0 \pm 0.0$ & $0.1 \pm 0.1$ \\
\hline Total $n-6$ & $8.2 \pm 2.3$ & $13.7 \pm 5.7$ & $17.5 \pm 0.9$ & $6.7 \pm 2.9$ & $10.3 \pm 1.9$ & $20.4 \pm 1.0$ & $11.4 \pm 6.3$ & $14.5 \pm 1.5$ & $19.9 \pm 3.4$ \\
\hline $18: 3 n-3$ & $0.1 \pm 0.1$ & $0.2 \pm 0.1$ & $0.3 \pm 0.1$ & & & & & & \\
\hline $20: 5 n-3$ & $0.2 \pm 0.1$ & $0.4 \pm 0.2$ & $0.7 \pm 0.5$ & $0.7 \pm 0.2$ & $1.7 \pm 0.4$ & $3.0 \pm 0.3$ & $0.2 \pm 0.1$ & $0.6 \pm 0.3$ & $1.3 \pm 0.4$ \\
\hline $22: 5 n-3$ & & $0.2 \pm 0.1$ & $0.3 \pm 0.0$ & $0.2 \pm 0.1$ & $0.6 \pm 0.3$ & $1.5 \pm 0.4$ & & & $0.3 \pm 0.2$ \\
\hline $22: 6 n-3$ & $0.1 \pm 0.1^{*}$ & $0.8 \pm 0.4^{*}$ & $1.4 \pm 0.2 * \dagger$ & $0.1 \pm 0.1$ & $1.2 \pm 0.4$ & $5.1 \pm 1.0$ & $2.2 \pm 1.5 \dagger$ & $3.6 \pm 0.9 \dagger$ & $6.6 \pm 1.7$ \\
\hline Total n-3 & $0.4 \pm 0.1 \neq$ & $1.7 \pm 0.7 \ddagger$ & $2.6 \pm 0.7 \ddagger$ & $0.9 \pm 0.4 \S$ & $3.4 \pm 0.8$ & $9.5 \pm 1.2$ & $2.4 \pm 1.6$ & $4.2 \pm 1.2$ & $8.1 \pm 2.0$ \\
\hline$n$ & 3 & 3 & 4 & 3 & 5 & 3 & 4 & 4 & 5 \\
\hline
\end{tabular}

* Different from respective time points for 22:6 diet, $p<0.01$.

+ Different from respective time points for 20:5 diet, $p<0.01$.

$\ddagger$ Different from respective time points for 20:5 and 22:6 diets, $p=0.043$.

$\S$ Different from respective time points for $22: 6$ diet, $p=0.043$.

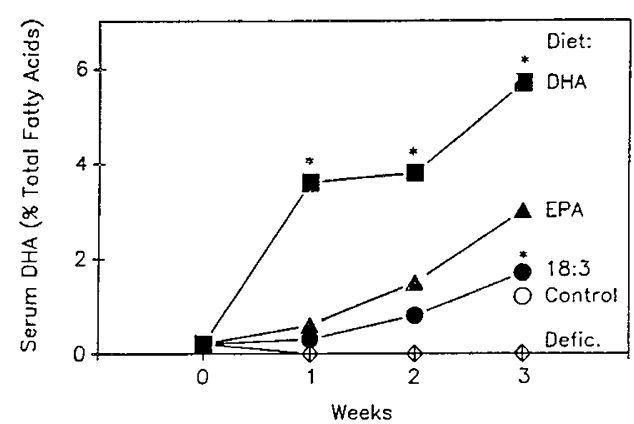

Fig. 4. Serum levels of DHA after the refeeding of $n$-3-deficient chicks with 18:3, EPA, or DHA (*different from the other two repletion diets at $p=0.02$ ).

serum DHA in chicks fed EPA and suggests that the brain and retina themselves were responsible for synthesis of a major part of the DHA that accumulated during the first 2 wk of EPA refeeding. Such synthesis implies that $\delta$-4-desaturase and the fatty acid elongation enzyme(s) were active in these tissues.

By 3 wk of life, levels of DHA were roughly equivalent in the livers of chicks fed either EPA or DHA. This suggests that the liver could have ultimately begun to contribute to the total body pool of DHA by synthesizing DHA from EPA. However, serum levels of DHA were still not equivalent in 3-wk-old chicks fed the EPA and DHA diets. In an earlier study, Edwards and Marion (37) also found evidence of elongation of dietary EPA to 22:5n3 in chick liver after a few weeks. Unfortunately, it was not possible in that report to distinguish between $22: 5 n-3$ formed from EPA and 22:5n-3 formed by retroconversion of DHA,

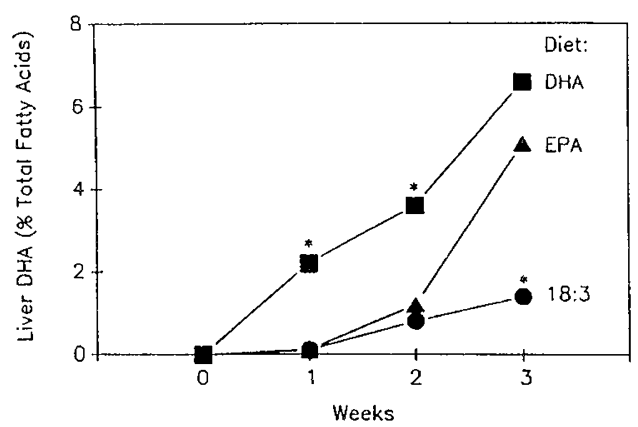

Fig. 5. Liver levels of DHA after the refeeding of n-3-deficient chicks with 18:3, EPA, or DHA (*different from the other two repletion diets at $p<0.01)$.

because the chicks were fed fish oil containing both EPA and DHA. The relative contribution of the liver and brain in this situation is more difficult to ascertain in nondeficient animals. For example, in humans (38) and rats (39), the liver has as high a level of DHA as the developing brain. Perhaps the immature chick liver, unlike the brain and retina, has less $\delta-4$ desaturase activity.

In previous reports using different dietary $n-3$ fatty acids, the extent to which the dietary fatty acid is incorporated into the brain has varied. For example, in some experiments involving the feeding of large amounts of $18: 3$ or fish oil to rats (40), chickens $(9,14,41)$, and monkeys (41a) the levels of EPA were increased to as much as $2 \%$ of total fatty acids in the brain. This fatty acid is usually present at a very low level, if at all, in the brain (26). Other studies have found little effect, however. Bourre 
et al. (17) fed cod liver oil (14.5\% wt:wt, containing $8.6 \%$ of fatty acids as EPA and $9.9 \%$ of fatty acids as DHA) to adult rats and found only a negligible change in brain EPA, although brain DHA did increase. Holub and coworkers (18) obtained similar results but found that EPA did increase substantially in the retina. Mice fed $10 \%$ fish oil (15) showed a transient rise in brain EPA, which mostly disappeared by $10 \mathrm{~d}$ of feeding. Some studies involving the feeding of large amounts of $18: 3 n-3$ also showed little effect on brain EPA levels $(42,43)$. In the present study, modest amounts (0.44\% of calories) of 18:3, EPA, and DHA were fed to n-3 fatty acid-deficient chicks, and generally no more than trace amounts of EPA appeared in the brain and retina.

Inasmuch as stores of $\mathrm{n}-3$ fatty acids in the tissues of the deficient chicks were minimal at the beginning of the repletion feeding, we were able to identify unambiguously the elongation and retroconversion products from each of the three $n-3$ fatty acids fed. Our finding that substantial amounts of dietary DHA are retroconverted to $22: 5 \mathrm{n}-3$ and EPA is in agreement with previous dietary and radiotracer studies $(29,44,45)$, and we have reported for the first time that small quantities of dietary EPA and DHA are retroconverted to $18: 3$ in the retina.

In summary, these findings have possible implications for the feeding of human infants with commercial formula preparations. The sole source of $\mathrm{n}-3$ fatty acids in these preparations is $\alpha$ linolenic acid (18:3n-3) and even this is at very low levels in some of the powdered formula preparations (W. E. Connor and S. Van Winkle, unpublished observations). However, human milk contains both DHA and 18:3 as sources of the essential $n$ 3 fatty acids (46). In chicks, DHA was the preferred dietary n-3 fatty acid for accumulation of DHA in the brain and retina, raising questions about the importance of dietary DHA in the development of other species, including the human infant.

Acknowledgement. The authors thank Dr. Gary Sexton for help with statistical analysis of the data.

\section{REFERENCES}

1. Anderson GJ, Connor WE, Corliss JD 1989 Comparative metabolism of linolenic, eicosapentaenoic, and docosahexaenoic acids in n-3 fatty acid deficient chicks. FASEB 3:A948(abstr)

2. Leaf A, Weber PC 1988 Cardiovascular effects of $n-3$ fatty acids. N Engl J Med 318:549-557

3. Herold PM, Kinsella JE 1986 Fish oil consumption and decreased risk of cardiovascular disease: a comparison of findings from animal and human feeding trials. Am J Clin Nutr 43:566-598

4. Neuringer M, Anderson GJ, Connor WE 1988 The essentiality of n-3 fatty acids for the development and function of the retina and brain. Annu Rev Nutr 8:517-541

5. Tinoco J 1982 Dietary requirements and functions of $\alpha$-linolenic acid in animals. Prog Lipid Res 21:1-45

6. Lamptey MS, Walker BL 1976 A possible essential role for dietary linolenic acid in the development of the young rat. J Nutr 106:86-93

7. Wheeler TG, Benolken RM, Anderson RE 1975 Visual membranes: specificity of fatty acid precursors for the electrical response to illumination. Science 188:1312-1314

8. Yamamoto N, Masaki S, Moriuchi A, Nomura M, Okuyama H 1987 Effect of dietary $\alpha$-linolenate/linoleate balance on brain lipid compositions and learning ability of rats. J Lipid Res 28:144-151

9. Anderson GJ, Connor WE, Corliss JD, Lin DS 1989 Rapid modulation of the $\mathrm{n}-3$ docosahexaenoic acid levels in the brain and retina of the newly-hatched chick. J Lipid Res 30:433-441

10. Grossman M, Bohren BB, Anderson VL 1985 Logistic growth curve of chickens: a comparison of techniques to estimate parameters. J Heredity 76:397399

11. Lawson LD, Hughes BG 1988 Human absorption of fish oil fatty acids as triacylglycerols, free acids, or ethyl esters. Biochem Biophys Res Commun $152: 328-335$

12. Winer BJ 1971 Statistical Principles in Experimental Design, 2nd ed. McGrawHill, New York, pp 445-449

13. Miller RG 1966 Simultaneous Statistical Inference. McGraw-Hill, New York, NY, pp 5-11

14. Miller D, Soares JH 1971 Comparative interaction and deposition of $w 3$ and w6 fatty acids in chick brain. Nutr Rept Intl 4:19-30

15. Swanson JE, Black JM, Kinsella JE 1988 Dietary menhaden oil: effects on the rate and magnitude of modification of phospholipid fatty acid composition of mouse heart and brain. Br J Nutr 59:535-545

16. Hwang DH, Boudreau M, Chanmugam P 1988 Dietary linolenic acid and longer-chain n-3 fatty acids: comparison of effects on arachidonic acid metabolism in rats. J Nutr 118:427-437

17. Bourre JM, Bonneil M, Dumont O, Piciotti M, Nalbone G, Lafont H 1988 High dietary fish oil alters the brain polyunsaturated fatty acid composition. Biochim Biophys Acta 960:458-461

18. Philbrick DJ, Mahadevappa VG, Ackman RG, Holub BJ 1987 Ingestion of fish oil or a derived n-3 fatty acid concentrate containing eicosapentaenoic acid (EPA) affects fatty acid compositions of individual phospholipids or rat brain, sciatic nerve and retina. J Nutr 117:1663-1670

19. Rogel AM, Watkins BA 1987 Liver subcellular fatty acid profiles of chicks fed diets containing hydrogenated fats and varying linoleate levels. Lipids 22:637-642

20. Youyou A, Durand G, Pascal G, Piciotti M, Dumont O, Bourre JM 1986 Recovery of altered fatty acid composition induced by a diet devoid of $n-3$ fatty acids in myelin, synaptosomes, mitochondria, and microsomes of developing rat brain. J Neurochem 46:224-228

21. Bourre JM, Youyou A, Durand G, Pascal G 1987 Slow recovery of the fatty acid composition of sciatic nerve in rats fed a diet initially low in $\mathbf{n}-3$ fatty acids. Lipids 22:535-538

22. Homayoun P, Durand G, Pascal G, Bourre JM 1988 Alteration in fatty acid composition of adult rat brain capillaries and choroid plexus induced by a diet deficient in $n-3$ fatty acids: slow recovery after substitution with a nondeficient diet. J Neurochem 51:45-48

23. Bourre J-M, Durand G, Pascal G, Youyou A 1989 Brain cell and tissue recovery in rats made deficient in $\mathrm{n}-3$ fatty acids by alteration of dietary fat. J Nutr 119:15-22

24. Leyton J, Drury PJ, Crawford MA 1987 Differential oxidation of saturated and unsaturated fatty acids in vivo in the rat. $\mathrm{Br} \mathbf{J}$ Nutr 57:383-393

25. Weiner TW, Sprecher H 1984 Arachidonic acid, 5,8,11-eicosatrienoic acid and $5,8,11,14,17$-eicosapentaenoic acid. Dietary manipulation of the levels of these acids in rat liver and platelet phospholipids and their incorporation into human platelet lipids. Biochim Biophys Acta 792:293-303

26. Neuringer M, Connor WE, Lin DS, Barstad L, Luck S 1986 Biochemical and functional effects of prenatal and postnatal omega-3 fatty acid deficiency on retina and brain in rhesus monkeys. Proc Natl Acad Sci USA 83:4021-4025

27. Dyerberg J, Bang HO, Aagaard O $1980 \alpha$-Linolenic acid and eicosapentaenoic acid. Lancet 1:199

28. Terano T, Hirai A, Hamazaki T, Kobayashi S, Fujita T, Tamura Y, Kumagai A 1983 Effect of oral administration of highly purified eicosapentaenoic acid on platelet function, blood viscosity and red cell deformability in healthy human subjects. Atherosclerosis 46:321-331

29. Von Schacky C, Weber PC 1985 Metabolism and effect on platelet function of the purified eicosapentaenoic and docosahexaenoic acids in humans. $J$ Clin Invest 76:2446-2450

30. Sanders TAB, Younger KM 1981 The effect of dietary supplements of w3 polyunsaturated fatty acids on the fatty acid composition of platelets and plasma choline phosphoglycerides. Br J Nutr 45:613-616

31. Carlson SE, Rhodes PG, Ferguson MG 1986 Docosahexaenoic acid status of preterm infants at birth and following feeding with human milk or formula. Am J Clin Nutr 44:798-804

32. Carlson SE, Rhodes PG, Rao VS, Goldgar DE 1987 Effect of fish oil supplementation on the n-3 fatty acid content of red blood cell membranes in preterm infants. Pediatr Res 21:507-510

33. Nouvelot A, Delbart C, Bourre JM 1986 Hepatic metabolism of dietary alphalinolenic acid in suckling rats, and its possible importance in polyunsaturated fatty acid uptake by the brain. Ann Nutr Metab 30:316-323

34. Naughton JM 1981 Supply of polyenoic fatty acids to the mammalian brain: the ease of conversion of the short-chain essential fatty acids to their longer chain polyunsaturated metabolites in liver, brain, placenta and blood. Int $J$ Biochem 13:21-32

35. Cook HW 1978 In vitro formation of polyunsaturated fatty acids by desaturation in rat brain: some properties of the enzymes in developing brain and comparisons with liver. J Neurochem 30:1327-1334

36. Cook HW 1982 Chain elongation in the formation of polyunsaturated fatty acids by brain: some properties of the microsomal system. Arch Biochem Biophys 214:695-704

37. Edwards HM, Marion JE 1963 Influence of dietary menhaden oil on growth rate and tissue fatty acids of the chick. J Nutr 81:123-129

38. Martinez M, Ballabriga A 1987 Effects of parenteral nutrition with high doses of linoleate on the developing human liver and brain. Lipids 22:133-138

39. Anderson GJ, Connor WE 1988 Uptake of fatty acids by the developing rat brain. Lipids 23:286-290

40. Odutuga AA 1981 Reversal of brain essential fatty-acid deficiency in the rat by dietary linoleate, linolenate and arachidonate. Int J Biochem 13:10351038

41. Budowski P, Leighfield MJ, Crawford MA 1987 Nutritional encephalomalacia in the chick: an exposure of the vulnerable period for cerebellar development and the possible need for both w6- and w3-fatty acids. Br $\mathrm{J}$ Nutr 58:511 520

41a. Connor WE, Neuringer M, Lin DS Dietary Effects upon brain fatty acid composition: the reversibility of $n-3$ fatty acid deficiency and turnover of docosahexaenoic acid in the brain, erythrocytes, and plasma of rhesus monkeys. J Lipid Res (in press)

42. Anding R, Hwang DH 1986 Effects of dietary linolenate on the fatty acid 
composition of brain lipids in rats. Lipids 21:697-701

43. Mohrhauer H, Holman RT 1963 Alteration of the fatty acid composition of brain lipids by varying levels of dietary essential fatty acids. $J$ Neurochem 10:523-530

44. Lokesh BR, Black JM, German JB, Kinsella JE 1988 Docosahexaenoic acid and other dietary polyunsaturated fatty acids suppress leukotriene synthesis by mouse peritoneal macrophages. Lipids 23:968-972

45. Hadjiagapiou C, Spector AA 1987 Docosahexaenoic acid metabolism and effect on prostacyclin production in endothelial cells. Arch Biochem Biophys 253:1-12

46. Harris WS, Connor WE, Lindsey S 1984 Will dietary omega-3 fatty acids change the composition of human milk? Am J Clin Nutr 40:780-785 